\title{
Clinical and Biological Significance of PD-L1 Expression Within the Tumor Microenvironment of Oral Squamous Cell Carcinoma
}

\author{
HIDEYUKI TAKAHASHI ${ }^{1}$, KOICHI SAKAKURA ${ }^{1}$, YUKIKO ARISAKA ${ }^{2}$, \\ AZUSA TOKUE ${ }^{2}$, KYOICHI KAIRA ${ }^{3,4}$, HIROE TADA ${ }^{1}$, TETSUYA HIGUCHI ${ }^{2}$, \\ AYAKO OKAMOTO $^{1}$, YOSHITO TSUSHIMA ${ }^{2}$ and KAZUAKI CHIKAMATSU ${ }^{1}$ \\ ${ }^{1}$ Department of Otolaryngology-Head and Neck Surgery, \\ Gunma University Graduate School of Medicine, Maebashi, Japan; \\ ${ }^{2}$ Department of Diagnostic Radiology and Nuclear Medicine, \\ Gunma University Graduate School of Medicine, Maebashi, Japan; \\ ${ }^{3}$ Department of Innovative Immune-Oncology Therapeutics, \\ Gunma University Graduate School of Medicine, Maebashi, Japan; \\ ${ }^{4}$ Department of Respiratory Medicine, Comprehensive Cancer Center, International \\ Medical Center, Saitama Medical University, Hidaka, Japan
}

\begin{abstract}
Background/Aim: Programmed death-ligand 1 (PD-L1) expression in tumor cells is regulated by a close interrelation between tumor and stromal cells within the tumor microenvironment. Our aim was to evaluate the clinical and biological significance of PD-L1 expression in oral squamous cell carcinoma (OSCC). Materials and Methods: PD-L1, cluster of differentiation (CD)4, CD8, and forkhead box $P 3$ (FOXP3) expression in tumor tissues obtained from 77 patients with OSCC was evaluated by immunohistochemical staining, and then analyzed for associations with clinical and biological factors. Results: Among the clinicopathological factors tested, only vascular invasion showed a trend toward lower PD-L1 expression ( $p=0.05)$. Metabolic tumor volume (MTV), and total lesion glycolysis (TLG) significantly positively correlated with $P D-L 1$ expression (MTV, $p=0.04 ; T L G, p=0.03)$. In patients with OSCC with high PD-L1 expression, those whose tumors had abundant infiltrating $C D 4^{+}$T-cells showed a longer progression-free survival than those with low $\mathrm{CD}^{+} \mathrm{T}$-cell infiltration ( $p=0.0452)$. Conclusion: As regulation of $P D-L 1$
\end{abstract}

Correspondence to: Kazuaki Chikamatsu, Department of Otolaryngology-Head and Neck Surgery, Gunma University Graduate School of Medicine, 3-39-22, Showa-machi, Maebashi, Gunma 3718511, Japan. Tel: +81 272208350, Fax: +81 272208369, e-mail: tikamatu@gunma-u.ac.jp

Key Words: PD-L1, tumor-infiltrating lymphocyte, oral squamous cell carcinoma, OSCC, tumor immune microenvironment, ${ }^{18} \mathrm{~F}$ fluorodeoxyglucose positron-emission tomography, ${ }^{18} \mathrm{~F}-\mathrm{FDG}-\mathrm{PET}$, glucose metabolism. expression is complex, its evaluation combined with other markers may be useful to determine clinical applications of PD-L1 expression.

Oral squamous cell carcinoma (OSCC) is one of the most common malignancies affecting the head and neck region, and the incidence has gradually been increasing over the past decades. Despite rapid advances in treatment modalities, including chemotherapy, radiotherapy, and target therapy, surgery is still a mainstream treatment for OSCC. Nowadays, emerging cancer immunotherapy using immune checkpoint blockade (ICB) has brought about drastic changes in the field of clinical oncology. In head and neck cancer, including OSCC, treatment with the anti-programmed death 1 (PD1) antibody nivolumab has resulted in longer overall survival than with standard, single-agent chemotherapy for patients with platinum-refractory, recurrent head and neck squamous cell carcinomas (HNSCC) (1). ICBs blockade the PD1/programmed death-ligand 1 (PD-L1) axis, which is a critical inhibitor of immune activation and plays an important role in tumor evasion of antitumor immune responses.

Although PD-L1 expression in OSCC has already been examined by immunohistochemistry and reported on (2-6), its clinical significance, including related prognosis, remains unclear. When it comes to assessment of PD-L1 expression in tumor cells, several points need to be considered, one of them being that PD-L1 expression is affected by the surrounding microenvironment. For instance, inflammatory conditions, hypoxia, or metabolic activity within the tumor microenvironment (TME) have been shown to change PDL1 expression in tumor cells (7-9). Thus, PD-L1 expression 
Table I. A semi-quantitative scoring method for evaluation of tumor-infiltrating lymphocytes (TILs).

\begin{tabular}{lccc}
\hline Score & Grade & TIL/tumor cell & Description \\
\hline 0 & Absent & $0 \%$ & Absence of TILs \\
1 & Mild & $<30 \%$ & Rare intratumoral cells, mostly perivascular \\
2 & Moderate & $30-60 \%$ & Focally present at periphery of tumor and/or intratumoral extending away from vessels \\
3 & Severe & $>60 \%$ & Either extending around the majority of the periphery of the tumor deposit, or diffusely present throughout tumor \\
\hline
\end{tabular}

in tumor cells is characterized by a close interrelation between tumor cells and stromal cells within the TME. Therefore, further elucidation of the clinical and biological significance of PD-L1 is urgently required for understanding the tumor immune microenvironment and further predicting the therapeutic efficacy of ICBs.

In this study, we first investigated PD-L1 expression in tumor cells in patients with OSCC by immunohistochemistry, and then analyzed the association with clinical and biological factors, including T-cell infiltration, clinical outcome, and glucose metabolism assessed using ${ }^{18} \mathrm{~F}$ fluorodeoxyglucose positron-emission tomography (FDGPET). Our results may suggest new insights into PD-L1 expression in tumor cells mediated by immune cells and glucose metabolism within the TME.

\section{Materials and Methods}

Patients and tissue samples. A total of 77 patients with OSCC who underwent radical surgery at Gunma University Hospital between November 2000 and January 2012 were enrolled in this study. All of the tumors were tongue cancer and diagnosed as SCC by experienced pathologists. Staging was undertaken according to the Union Internationale Contre le Cancer/American Joint Committee on Cancer TNM classification (10). We evaluated clinico-pathological factors, including age, sex, histological grade, primary tumor, involvement of regional lymph nodes, stage, lymphatic/vascular invasion, Ki-67 and CD34 staining, progression-free survival (PFS), and overall survival (OS). This study was approved by the Institutional Review Board of Gunma University (no. 2017-152).

Immunohistochemical staining. PD-L1, cluster of differentiation (CD)4, CD8, and forkhead box P3 (FOXP3) expression in tumor tissues obtained from patients with OSCC were examined by immunohistochemical staining, which was performed according to procedures reported in previous studies $(11,12)$. Briefly, serial histological sections $(2-\mu \mathrm{m}$-thick) were deparaffinized, and then endogenous peroxidase activity was blocked. Antigen retrieval was achieved by Immunosaver (NJ15T; NEM, Tokyo, Japan) at 98$100^{\circ} \mathrm{C}$ for $30 \mathrm{~min}$ for $\mathrm{CD} 4, \mathrm{CD} 8$, and FOXP3, and by Universal HIER antigen retrieval reagent (Abcam, Cambridge, UK) at $120^{\circ} \mathrm{C}$ for $20 \mathrm{~min}$ for PD-L1. Sections were then incubated with Protein Block Serum-Free Reagent (Dako, Carpinteria, CA, USA) for 30 min at room temperature. Samples were incubated with primary antibody (diluted by Dako REAL ${ }^{\mathrm{TM}}$ antibody diluent) overnight at $4^{\circ} \mathrm{C}$. The following antibodies were used: PD-L1 (E1L3N ${ }^{R}$ Rabbit
mAb, 1:200 dilution; Cell Signaling Technology Inc., Danvers, MA, USA), CD4 (EPR19514, 1:500 dilution; Abcam), CD8 (ab4055, 1:1000 dilution; Abcam), and FOXP3 (236A/E7 1:200 dilution; Abcam). Horseradish peroxidase-conjugated Histofine ${ }^{\circledR}$ Simple Stain $^{\mathrm{TM}}$ AP (MULTI) (N-Nichirei Biosciences Inc., Tokyo, Japan) and SignalStain(R) Boost IHC Detection Reagent (Cell Signaling) was used as the secondary antibody. In addition to PD-L1 expression and immune cell infiltration, CD34 staining was performed as per our previous study (13).

Evaluation of immunohistochemical staining. Slides were evaluated by at least two of the Authors in a blinded manner, using a light microscope. The expression of PD-L1 was considered positive when membranous staining was observed. A semi-quantitative scoring method was used for PD-L1: $0=<1 \%, 1=1-5 \%, 2=5-10 \%, 3=10$ $25 \%, 4=25-50 \%$, and $5=>50 \%$ of cells. Tumors with scores $>3$ were graded as having high expression. CD4, CD8 and FOXP3 were semi-quantitatively evaluated by the extent of positive lymphocytes infiltrating tumor specimens (Table I). We defined the samples as having high infiltration when they had tumor-infiltrating lymphocytes of more than $60 \%$ (score 3 ). Microvessel density (MVD) was evaluated as the mean $\mathrm{CD} 34^{+}$vessel count in four selected high-power fields $\left(\times 400,0.26 \mathrm{~mm}^{2}\right.$ field area).

PET imaging and data analysis. As 28 out of 77 patients with OSCC had undergone preoperative FDG-PET, PET parameters including maximal standardized uptake value $\left(\mathrm{SUV}_{\max }\right)$, metabolic tumor volume (MTV), and total lesion glycolysis (TLG) were calculated, as described previously (12). Briefly, PET imaging was performed using a PET/computed tomography scanner (Discovery STE; GE Healthcare, Chicago, IL, USA) with a $700 \mathrm{~mm}$ field of view, at Gunma University Hospital. Three-dimensional data acquisition was initiated $50 \mathrm{~min}$ after injecting $5 \mathrm{MBq} / \mathrm{kg}$ of FDG. All ${ }^{18} \mathrm{~F}-\mathrm{FDG}$ images were interpreted by two experienced nuclear physicians who were unaware of the patient's clinical history and data. SUV was defined as follows: SUV=radioactive concentration in the region of interest $(\mathrm{ROI})(\mathrm{MBq} / \mathrm{g}) /$ injected dose $(\mathrm{MBq}) /$ patient's body weight (g). The ROI was manually drawn over the primary tumor on the SUV images. The maximal SUV ( $\mathrm{SUV}_{\max }$ in the ROI was used as a representative value for the assessment of FDG uptake in the lesion. We used syngo.via software (Siemens Medical Solutions, Erlangen, Germany) on a workstation to automatically calculate the MTV and TLG, defined as MTV multiplied by SUVmean of each lesion, using an SUV threshold of 2.5 .

Statistical analysis. Statistical analysis was performed using GraphPad Prism version 6.0 for Windows (GraphPad Software, San Diego, CA, USA) and EZR (Saitama Medical Center, Jichi Medical University, Saitama, Japan), which is a graphical user interface for 
R (The R Foundation for Statistical Computing, Vienna, Austria). The Mann-Whitney $U$-test, Chi-squared test for independence, and Fisher's exact test were used to examine the association between continuous and categorical variables. $p$-Values of less than 0.05 were considered significant. PFS and OS were estimated using Kaplan-Meier survival curves and the log-rank test was used to compare the survival between two groups.

\section{Results}

Patient characteristics. The clinicopathological characteristics of all 77 patients are summarized in Table I. There were 27 female and 50 male patients, with a median age of 69 years (range=33-92 years). In terms of degree of tumor differentiation, 34 tumors had good differentiation, 31 moderate differentiation, and 12 poor differentiation. The TNM staging classification was stages I-II in 50 patients and stages III-IV in 27. Thirty-four and 25 tumors had lymphatic invasion and vascular invasion, respectively.

Expression of $P D-L 1$ and T-cell infiltration in OSCC. Representative slides of PD-L1, CD4, CD8 and FOXP3 are shown in Figure 1. Among the 77 patients tested, scores for PD-L1 expression in tumor cells were distributed as follows: score 0: nine patients (12\%); score 1: $8(10 \%)$; score 2: 14 (18\%); score 3: $11(14 \%)$; score 4: 9 (12\%); and score 5: 26 (34\%). Thirty-one (40\%) patients had tumors with low PDL1 expression, and the remaining $46(60 \%)$ had tumors with high PD-L1 expression. Similarly, positive-cell infiltration by three T-cell subsets, CD8, CD4, and FOXP3, was also evaluated. Patients with high T-cell infiltration numbered 16 $(21 \%)$ for $\mathrm{CD}^{+}, 19(25 \%)$ for $\mathrm{CD}^{+}$, and seven $(10 \%)$ for $\mathrm{FOXP}^{+} \mathrm{T}$-cells, respectively.

Correlation of PD-L1 expression with clinicopathological factors. We analyzed the correlation between PD-L1 expression level and various clinicopathological factors, including MVD and Ki-67 index (Table II). Only vascular invasion showed a trend toward lower PD-L1 expression, but this did not reach statistical significance $(p=0.05)$. PD-L1 expression did not show a significant correlation with any of the other clinicopathological factors tested. Moreover, there was no significant relationship between any form of T-cell infiltration and PD-L1 expression in tumor cells.

Correlation of PD-L1 expression with glycolytic metabolism (PET parameters). Three parameters, $\mathrm{SUV}_{\max }, \mathrm{MTV}$ and TLG, were measured in 28 patients who underwent FDG-PET. Although $\mathrm{SUV}_{\text {max }}$ did not correlate with PD-L1 expression in OSCC, MTV and TLG significantly positively correlated with PD-L1 expression (MTV, $p=0.04$; TLG, $p=0.03$, Table III).

Survival analysis in patients with OSCC with PD-L1 expression. Univariate survival analysis regarding PFS and
Table II. Patient characteristics according to programmed death-ligand 1 (PD-L1) expression.

PD-L1 score

\begin{tabular}{|c|c|c|c|c|}
\hline Variable & Total $(n=77)$ & $0-2(n=31)$ & $3-5(n=46)$ & $p$-Value \\
\hline \multicolumn{5}{|l|}{ Age } \\
\hline Median (range) & $69(33-92)$ & $71(33-84)$ & $69(38-92)$ & 0.88 \\
\hline \multicolumn{5}{|l|}{ Gender, $\mathrm{n}$} \\
\hline Female & 27 & 9 & 18 & \multirow[t]{2}{*}{0.36} \\
\hline Male & 50 & 22 & 28 & \\
\hline \multicolumn{5}{|l|}{ Differentiation, $\mathrm{n}$} \\
\hline WD & 34 & 11 & 23 & \multirow[t]{3}{*}{0.42} \\
\hline MD & 31 & 15 & 16 & \\
\hline PD & 12 & 5 & 7 & \\
\hline \multicolumn{5}{|l|}{ T Factor, $\mathrm{n}$} \\
\hline $\mathrm{T} 1-2$ & 65 & 27 & 38 & \multirow[t]{2}{*}{0.75} \\
\hline T3-4 & 12 & 4 & 8 & \\
\hline \multicolumn{5}{|l|}{$\mathrm{N}$ Factor, $\mathrm{n}$} \\
\hline $\mathrm{N}-$ & 51 & 20 & 31 & \multirow[t]{2}{*}{0.79} \\
\hline $\mathrm{N}+$ & 26 & 11 & 15 & \\
\hline \multicolumn{5}{|l|}{ Disease stage, $n$} \\
\hline Early & 50 & 19 & 31 & \multirow[t]{2}{*}{0.58} \\
\hline Advanced & 27 & 12 & 15 & \\
\hline \multicolumn{5}{|c|}{ Lymphatic invasion, $\mathrm{n}$} \\
\hline Negative & 43 & 18 & 25 & \multirow[t]{2}{*}{0.74} \\
\hline Positive & 34 & 13 & 21 & \\
\hline \multicolumn{5}{|c|}{ Vascular invasion, $\mathrm{n}$} \\
\hline Negative & 52 & 17 & 35 & \multirow[t]{2}{*}{0.05} \\
\hline Positive & 25 & 14 & 11 & \\
\hline \multicolumn{5}{|c|}{$\mathrm{CD} 4^{+}{ }^{+}$vessel count } \\
\hline Median (range) & $14(2-29)$ & $15(2-26)$ & $14(2-29)$ & 0.66 \\
\hline \multicolumn{5}{|l|}{$\mathrm{Ki}-67, \%$} \\
\hline Median (range) & $21(3-72)$ & $25(5-60)$ & $20.5(3-72)$ & 0.59 \\
\hline \multicolumn{5}{|c|}{$\mathrm{CD}^{+}{ }^{+}$cell infiltration, $\mathrm{n}$} \\
\hline $0-2$ & 61 & 25 & 36 & \multirow[t]{2}{*}{0.80} \\
\hline 3 & 16 & 6 & 10 & \\
\hline \multicolumn{5}{|c|}{$\mathrm{CD}^{+}+$cell infiltration, $\mathrm{n}$} \\
\hline $0-2$ & 58 & 21 & 37 & \multirow[t]{2}{*}{0.21} \\
\hline 3 & 19 & 10 & 9 & \\
\hline \multicolumn{5}{|l|}{$\begin{array}{l}\text { FOXP3 }^{+} \text {cell } \\
\text { infiltration, } \mathrm{n}\end{array}$} \\
\hline $0-2$ & 65 & 27 & 38 & \multirow[t]{3}{*}{0.95} \\
\hline 3 & 7 & 3 & 4 & \\
\hline Unknown & 5 & 1 & 4 & \\
\hline
\end{tabular}

WD, Well-differentiated; MD, moderately differentiated; PD, poorly differentiated; CD: cluster of differentiation; FOXP3: forkhead box P3.

OS was performed using Cox's proportional hazards regression model to evaluate the prognostic value of PD-L1 expression and the three T-cell subsets. As shown in Table IV, none of these significantly influenced PFS nor OS on univariate analysis. A Kaplan-Meier survival analysis was also performed on PD-L1 expression; unfortunately, no significant difference was observed (Figure 2).

The expression of PD-L1 in tumor cells is partially regulated by the surrounding inflammatory environment; 


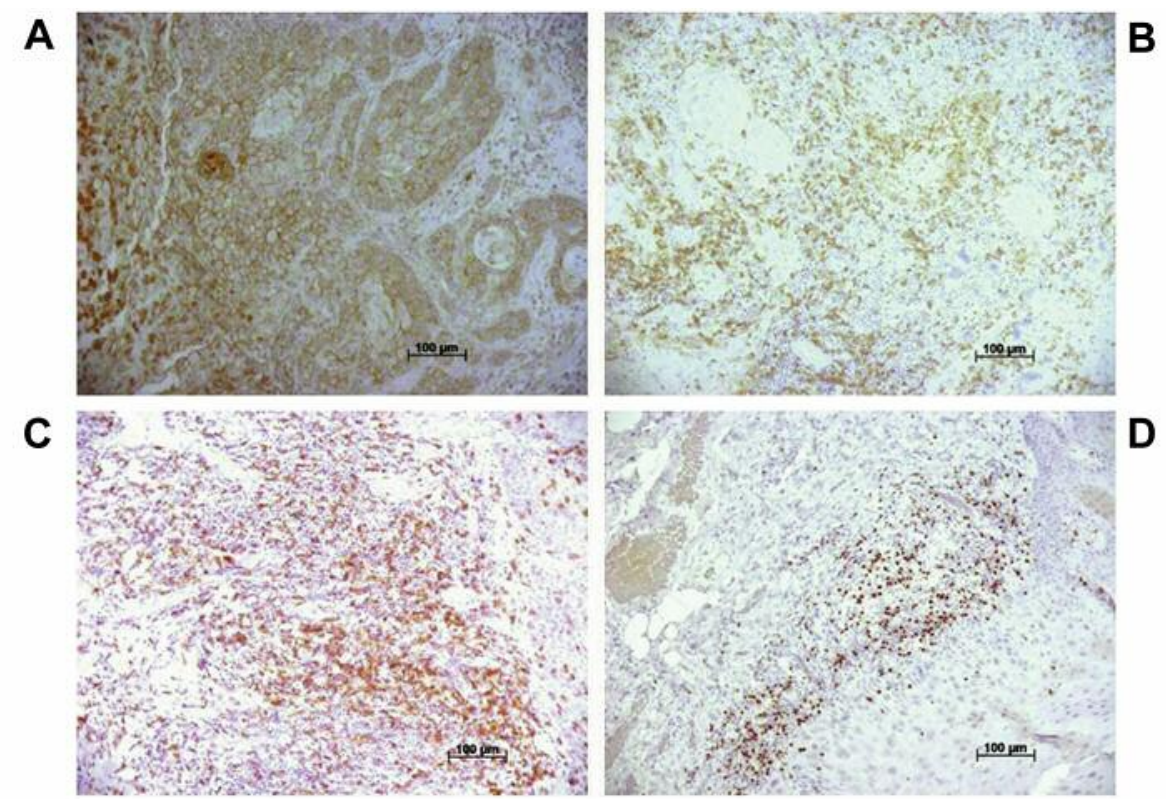

Figure 1. Representative immunohistochemical images of programmed death-ligand 1 (PD-L1), cluster of differentiation (CD)8, CD4, and forkhead box P3 (FOXP3) staining. The expression of PD-L1 was considered positive when membranous staining was observed. A semi-quantitative scoring method was used as described in the Materials and Methods. A: Example of high PD-L1 expression. For PD-L1, tumors with a score $>3$ (>10\% positivity) were graded as having high expression ( $\times 100$ magnification). Examples of high $\mathrm{CD} 8^{+}(B), C D 4^{+}(C)$ and $F O X P 3^{+}(D)$ lymphocyte infiltration. Tumors with more than $60 \%$ positive lymphocytes (score 3$)$ were defined as having a high infiltration ( $\times 100$ magnification).

therefore, the patients with OSCC with high PD-L1 expression were divided into two groups according to T-cell infiltration, and Kaplan-Meier analysis was performed (Figure 3). Interestingly, in those with high PD-L1 expression, those whose tumor had abundant infiltrating $\mathrm{CD} 4^{+}$T-cells had a significantly longer PFS compared with those with low $\mathrm{CD}^{+}$ T-cell infiltration ( $p=0.0452$, Figure 3C).

\section{Discussion}

Previous studies on OSCC have demonstrated PD-L1 expression in $18 \%$ to $87 \%$ of patients (14), and the proportion of the PD-L1-positive population varied, due to differences in antibody used, methods for evaluation, and type of samples (15). In the present study, $46(60 \%)$ out of 77 patients with OSCC had high PD-L1 expression. HNSCC, including OSCC, has a high frequency and high intensity of PD-L1 expression (16); therefore, our samples were divided into two groups, with low and high expression by a defined cutoff value of $10 \%$ positivity. Although it is already wellknown that PD-L1 in tumor cells is responsible for induction and maintenance of immunosuppression within the TME, the clinical significance of PD-L1 expression remains elusive in a variety of cancer types, including OSCC. To date, PD-L1 expression in OSCC has been reported to correlate with adverse factors, including nodal metastasis, stage, and distant metastasis $(3,5,6,17)$. In our study, there was no significant correlation with any clinicopathological factors, including $\mathrm{T}$ cell infiltration.

Of the various clinicopathological factors analyzed, only a trend was observed toward an inverse association between PD-L1 expression and vascular invasion within the TME. Meng et al. demonstrated PD-L1 overexpression in cervical cancer to be significantly associated with vascular invasion (18). Characteristics of vascular invasion are closely related to intratumoral angiogenesis, and various factors, including vascular endothelial growth factor, hepatocyte growth factor, and interleukin-1 $\beta$ are produced from tumor cells as well as stromal cells, and may induce or enhance PD-L1 expression in tumor cells $(19,20)$. Our results partially failed to show accordance with the previous reports, but two points are of particular interest: a correlation of PD-L1 with glucose metabolism using PET parameters, and clinical significance of PD-L1 expression associated with $\mathrm{CD} 4^{+} \mathrm{T}$-cell infiltration.

Recently, Chang et al. showed that tumor PD-L1 expression promoted glycolytic metabolism through metabolic competition for glucose between tumor cells and tumorinfiltrating lymphocytes within the TME (21). Other studies found that hypoxia in the TME caused by rapid proliferation of tumor cells induces upregulation of HIF-1 $\alpha$ expression, and HIF- $1 \alpha$ activation can result in the up-regulation of PD-L1 as well as of glycolysis $(9,22,23)$. Thus, accumulating evidence 

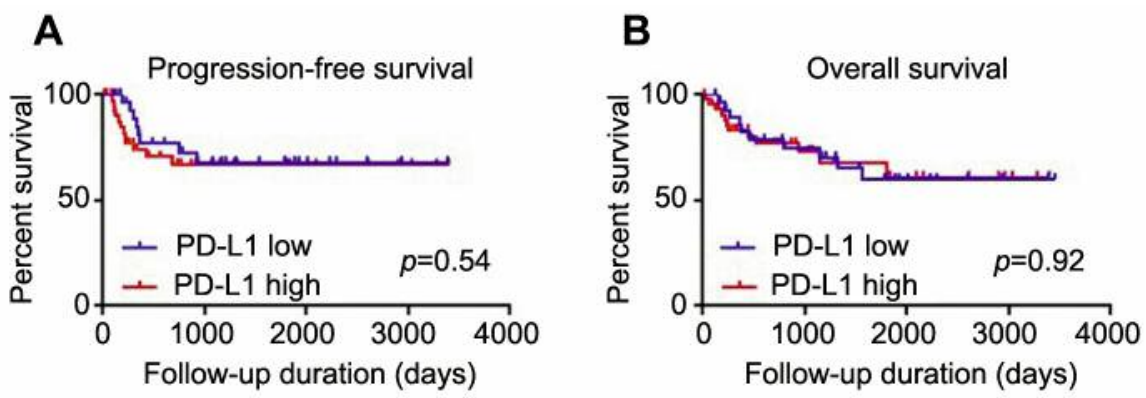

Figure 2. Kaplan-Meier curve and log-rank test for progression-free survival (A) and overall survival (B) according to programmed death-ligand 1 (PD-L1) expression.
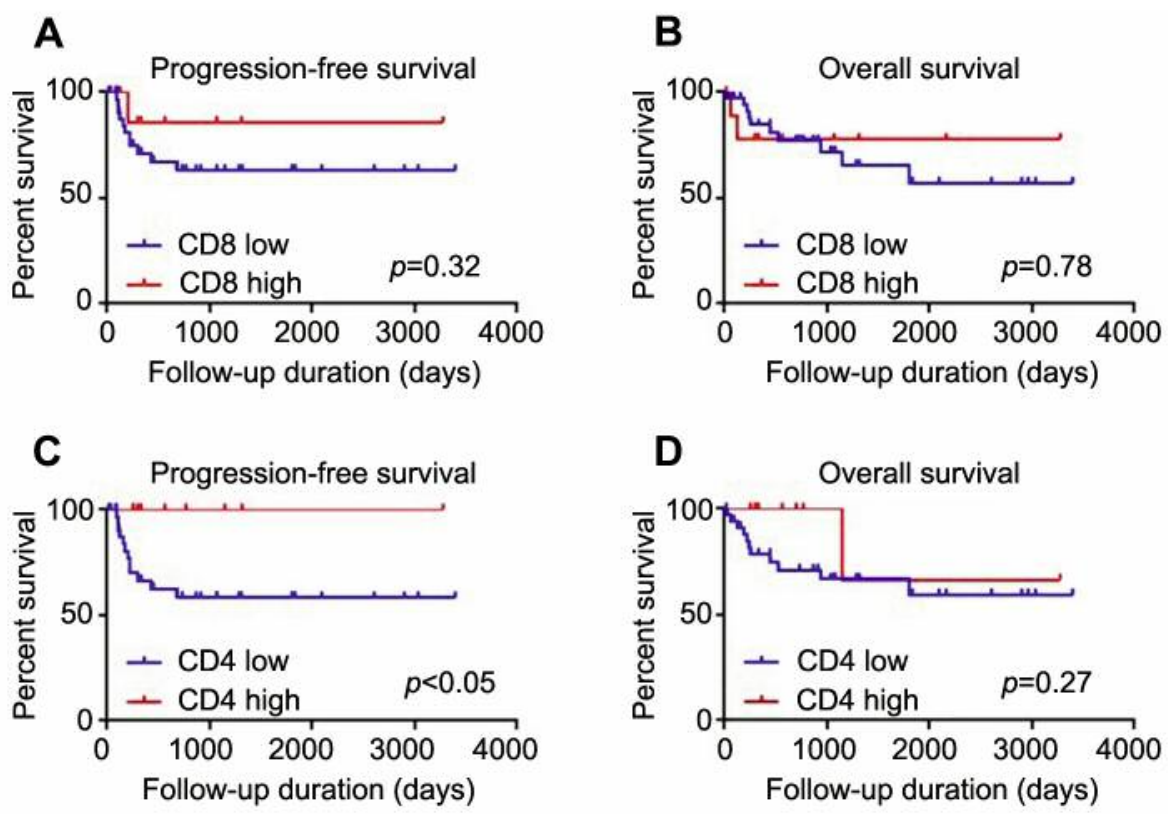

Figure 3. Kaplan-Meier curve and log-rank test for progression-free survival ( $A$ and $C)$ and overall survival $(B$ and $D)$ of patients with high programmed death-ligand 1 (PD-L1) expression according to cluster of differentiation $(C D) 8^{+}(A$ and $B)$ and $C D 4^{+}(C$ and $D) T$-cell infiltration .

indicates that in tumor cells, PD-L1 expression is closely related to glycolytic metabolism.

As tumoral uptake of ${ }^{18} \mathrm{~F}-\mathrm{FDG}$ is based on enhanced glycolysis, PET parameters might be used as markers for tumor glycolysis. Actually, PD-L1 expression in lung cancer has been shown to be significantly correlated with $\mathrm{SUV}_{\max }$ in ${ }^{18}$ F-FDG-PET $(24,25)$. As in our study 28 out of 73 patients with OSCC had undergone ${ }^{18} \mathrm{~F}$-FDG-PET, data on three PET parameters, $\mathrm{SUV}_{\max }$, MTV, and TLG, were available; therefore, we investigated whether PD-L1 expression in OSCC was related to glycolytic metabolism within the TME using PET parameters. As expected, two PET parameters, MTV and TLG, obtained from patients with high PD-L1 expression were significantly higher than in those with low PD-L1 expression, suggesting that MTV and
TLG may reflect not only tumor glycolysis, but also total PD-L1 expression in the tumor lesion.

More recently, the prediction of response to ICBs using ${ }^{18} \mathrm{~F}$ FDG-PET has been reported (12). As immunohistochemical evaluation for PD-L1 expression appears to be difficult, due to heterogeneous and altering expression, PD-L1 positivity by immunohistochemistry is not suitable as a definite biomarker that predicts therapeutic response to ICBs. In contrast to immunohistochemistry, PET imaging may become a useful tool for comprehensive evaluation of TME, including PD-L1 status and tumor metabolism.

Regarding the prognostic value of PD-L1 in tumor cells, in our study PD-L1 expression in OSCC did not correlate with prognosis. The prognostic significance of PD-L1 expression in OSCC is still controversial; that is, PD-L1 expression in 
Table III. Correlation of programmed death-ligand 1 (PD-L1) expression and glycolytic metabolism (positron-emission tomography parameters).

\begin{tabular}{lcccc}
\hline & \multicolumn{3}{c}{ PD-L1 score } & \\
\cline { 2 - 3 } Variable & Total $(\mathrm{n}=28)$ & $0-2(\mathrm{n}=9)$ & $3-5(\mathrm{n}=19)$ & \\
\hline $\begin{array}{l}\text { SUV } \\
\text { Median }\end{array}$ & & & & \\
MTV (range) & $10.5(3.3-32.2)$ & $9.7(3.3-17.9)$ & $10.9(5.3-32.2)$ & 0.26 \\
$\quad \begin{array}{l}\text { Median (range) } \\
\text { TLG } \\
\text { Median (range) }\end{array}$ & $16.8(1.1-91.2)$ & $10.6(1.1-33.5)$ & $25.7(3.3-91.2)$ & 0.04 \\
\hline
\end{tabular}

$\mathrm{SUV}_{\max }$ : Maximum standardized uptake value; MTV: metabolic tumor volume; TLG: total lesion glycolysis.

Table IV. Univariable survival analysis in all patients with oral squamous cell carcinoma.

\begin{tabular}{|c|c|c|c|c|c|c|c|}
\hline \multirow[t]{2}{*}{ Variable } & & \multicolumn{3}{|c|}{ Overall survival } & \multicolumn{3}{|c|}{ Progression-free survival } \\
\hline & & HR & $95 \% \mathrm{CI}$ & $p$-Value & HR & $95 \% \mathrm{CI}$ & $p$-Value \\
\hline \multirow[t]{2}{*}{ PD-L1 } & $0-2$ & 1 & & 0.92 & 1 & & 0.54 \\
\hline & $3-5$ & 1.04 & $0.45-2.42$ & & 1.32 & $0.54-3.24$ & \\
\hline \multirow[t]{2}{*}{$\mathrm{CD}^{+}$cell infiltration } & $0-2$ & 1 & & 0.31 & 1 & & 0.20 \\
\hline & 3 & 0.53 & $0.16-1.80$ & & 0.39 & $0.09-1.68$ & \\
\hline \multirow[t]{2}{*}{$\mathrm{CD}^{+}{ }^{+}$cell infiltration } & $0-2$ & 1 & & 0.40 & 1 & & 0.08 \\
\hline & 3 & 0.63 & $0.21-1.86$ & & 0.27 & $0.06-1.17$ & \\
\hline \multirow{2}{*}{$\mathrm{FOXP}^{+}$cell infiltration } & $0-2$ & 1 & & 0.45 & 1 & & 0.50 \\
\hline & 3 & 0.46 & $0.06-3.48$ & & 0.50 & $0.07-3.78$ & \\
\hline
\end{tabular}

PD-L1: Programmed death-ligand 1; CD: cluster of differentiation; FOXP3: forkhead box P3; HR: hazard ratio; 95\% CI: $95 \%$ confidence interval.

OSCC has been reported to be associated with poor prognosis $(6,16,26)$, and better prognosis $(27,28)$, or not associated with prognosis at all $(2,4)$. Through a meta-analysis of 1,060 patients with OSCC, Troiano et al. demonstrated that high PD-L1 expression did not correlate with poor prognosis (29). Similarly, Yang et al. also showed that PD-L1 expression detected by immunohistochemistry was not recommended for predicting survival in patients with HNSCC (30).

PD-L1 expression mechanisms in tumor cells consist of two different pathways: the oncogenic pathway, and reflection of immune responses mediated by Janus kinase/signal transducers and activators of transcription signaling (31). The balance of these two mechanisms in the TME of OSCC is currently unknown, but the latter could play a pivotal role in the regulation of PD-L1 expression in tumor cells, especially because interferon $\gamma$ produced by $\mathrm{T}$ cells mainly up-regulates PD-L1 expression in tumor cells (32). Moreover, transcriptomic data from 280 HNSCC tumors profiled by The Cancer Genome Atlas showed that HNSCC was one of the most immune-infiltrated tumors, and T-cell infiltration score correlated with relative interferon $\gamma$ expression (33).
Based on these findings, patients with OSCC with high PDL1 expression were classified into two groups according to $\mathrm{T}$ cell infiltration: in patients with high $\mathrm{CD} 4^{+} \mathrm{T}$-cell infiltration there was benefit in PFS compared to those with low infiltration, suggesting that in such patients, abundant infiltrating $\mathrm{CD}^{+}{ }^{+} \mathrm{T}$-cells may exert antitumor immune responses through interferon $\gamma$ production within the TME and result in upregulation of PD-L1 in tumor cells. In general, tumor progression, invasion, and metastasis are recognized to depend on pre-existing immunity, which could determine not only the clinical outcome of the patients but also the likelihood of response to ICBs. Thus, the distinction of PD-L1 expression in tumor cells based on antitumor immunity within the TME could be important for the evaluation of prognostic significance.

Taken together, clinical and biological significance of PDL1 expression assessed by immunohistochemistry in OSCC is still elusive; however, comprehensive evaluation of PD-L1 expression within the TME might be more important in clinical practice, including the clinical effect of ICBs. For this purpose, use of functional imaging modalities such as FDGPET and the development of evaluation methods associated with immune cell infiltration should be considered. 


\section{Acknowledgements}

This work was supported, in part, by a Grant-in-Aid for Scientific Research (C) 17K11374 (K.C.) from the Ministry of Education, Culture, Sports, Science and Technology, Japan.

\section{Disclosure of Interest}

None of the Authors have any financial or personal relationship with other people or organizations that inappropriately influenced this study.

\section{Authors' Contributions}

Conception or design of the work: Kyoichi Kaira, Kazuaki Chikamatsu. Data collection: Koichi Sakakura, Kyoichi Kaira, Yukiko Arisaka, Azusa Tokue, Hiroe Tada, Ayako Okamoto. Data analysis and interpretation: Hideyuki Takahashi, Tetsuya Higuchi, Yoshito Tsushima, Kazuaki Chikamatsu. Article preparation: Hedeyuki Takahashi, Kazuaki Chikamatsu. Final approval of the version to be published: Yoshito Tsushima, Kazuaki Chikamatsu.

\section{References}

1 Ferris RL, Blumenschein G Jr., Fayette J, Guigay J, Colevas AD, Licitra L, Harrington K, Kasper S, Vokes EE, Even C, Worden F, Saba NF, Iglesias Docampo LC, Haddad R, Rordorf T, Kiyota N, Tahara M, Monga M, Lynch M, Geese WJ, Kopit J, Shaw JW and Gillison ML: Nivolumab for recurrent squamous-cell carcinoma of the head and neck. N Engl J Med 375(19): 18561867, 2016. PMID: 27718784. DOI: 10.1056/NEJMoa 1602252

2 Cho YA, Yoon HJ, Lee JI, Hong SP and Hong SD: Relationship between the expression of PD-L1 and tumor-infiltrating lymphocytes in oral squamous cell carcinoma. Oral Oncol 47(12): 1148-1153, 2011. PMID: 21911310. DOI: 10.1016/ j.oraloncology.2011.08.007

3 Lin YM, Sung WW, Hsieh MJ, Tsai SC, Lai HW, Yang SM, Shen KH, Chen MK, Lee H, Yeh KT and Chen CJ: High PD-L1 expression correlates with metastasis and poor prognosis in oral squamous cell carcinoma. PLoS One 10(11): e0142656, 2015. PMID: 26562534. DOI: 10.1371/journal.pone.0142656

4 Satgunaseelan L, Gupta R, Madore J, Chia N, Lum T, Palme CE, Boyer M, Scolyer RA and Clark JR: Programmed cell deathligand 1 expression in oral squamous cell carcinoma is associated with an inflammatory phenotype. Pathology 48(6): 574-580, 2016. PMID: 27590194. DOI: 10.1016/j.pathol. 2016.07.003

5 Oliveira-Costa JP, de Carvalho AF, da Silveira da GG, Amaya P, Wu Y, Park KJ, Gigliola MP, Lustberg M, Buim ME, Ferreira EN, Kowalski LP, Chalmers JJ, Soares FA, Carraro DM and Ribeiro-Silva A: Gene expression patterns through oral squamous cell carcinoma development: PD-L1 expression in primary tumor and circulating tumor cells. Oncotarget 6(25): 20902-20920, 2015. PMID: 26041877. DOI: 10.18632/ oncotarget.3939

6 Straub M, Drecoll E, Pfarr N, Weichert W, Langer R, Hapfelmeier A, Gotz C, Wolff KD, Kolk A and Specht K: CD274/PD-L1 gene amplification and PD-L1 protein expression are common events in squamous cell carcinoma of the oral cavity. Oncotarget 7(11): 12024-12034, 2016. PMID: 26918453. DOI: $10.18632 /$ oncotarget.7593
7 Barsoum IB, Smallwood CA, Siemens DR and Graham CH: A mechanism of hypoxia-mediated escape from adaptive immunity in cancer cells. Cancer Res 74(3): 665-674, 2014. PMID: 24336068. DOI: 10.1158/0008-5472.CAN-13-0992

8 Ritprajak P and Azuma M: Intrinsic and extrinsic control of expression of the immunoregulatory molecule PD-L1 in epithelial cells and squamous cell carcinoma. Oral Oncol 51(3): 221-228, 2015. PMID: 25500094. DOI: 10.1016/j.oraloncology. 2014.11.014

9 Lim S, Phillips JB, da Silva LM, Zhou M, Fodstad O, Owen LB and Tan M: Interplay between immune checkpoint proteins and cellular metabolism. Cancer Res 77(6): 1245-1249, 2017. PMID: 28246276. DOI: 10.1158/0008-5472.CAN-16-1647

10 Sobin L, Gospodarowicz and Wittekind C (eds.): TNM Classification of Malignant Tumors, Seventh Edition. Hoboken, New Jersey, USA, Wiley-Blackwell, 2010.

11 Kasahara N, Kaira K, Bao P, Higuchi T, Arisaka Y, ErkhemOchir B, Sunaga N, Ohtaki Y, Yajima T, Kosaka T, Oyama T, Yokobori T, Asao T, Nishiyama M, Tsushima Y, Kuwano H, Shimizu K and Mogi A: Correlation of tumor-related immunity with ${ }^{18}$ F-FDG-PET in pulmonary squamous cell carcinoma. Lung Cancer 119: 71-77, 2018. PMID: 29656756. DOI: 10.1016/j.lungcan.2018.03.001

12 Kaira K, Higuchi T, Naruse I, Arisaka Y, Tokue A, Altan B, Suda S, Mogi A, Shimizu K, Sunaga N, Hisada T, Kitano S, Obinata $\mathrm{H}$, Yokobori T, Mori K, Nishiyama M, Tsushima Y and Asao T: Metabolic activity by ${ }^{18} \mathrm{~F}-\mathrm{FDG}-\mathrm{PET} / \mathrm{CT}$ is predictive of early response after nivolumab in previously treated NSCLC. Eur J Nucl Med Mol Imaging 45(1): 56-66, 2018. PMID: 28828507. DOI: $10.1007 / \mathrm{s} 00259-017-3806-1$

13 Yokobori Y, Toyoda M, Sakakura K, Kaira K, Tsushima Y and Chikamatsu K: ${ }^{18}$ F-FDG uptake on PET correlates with biological potential in early oral squamous cell carcinoma. Acta Otolaryngol 135(5): 494-499, 2015. PMID: 25739639. DOI: 10.3109/00016489.2014.969385

14 De Meulenaere A, Vermassen T, Aspeslagh S, Huvenne W, Van Dorpe J, Ferdinande L and Rottey S: Turning the tide: Clinical utility of PD-L1 expression in squamous cell carcinoma of the head and neck. Oral Oncol 70: 34-42, 2017. PMID: 28622889. DOI: $10.1016 /$ j.oraloncology.2017.05.002

15 Rimm DL, Han G, Taube JM, Yi ES, Bridge JA, Flieder DB, Homer R, West WW, Wu H, Roden AC, Fujimoto J, Yu H, Anders R, Kowalewski A, Rivard C, Rehman J, Batenchuk C, Burns V, Hirsch FR and Wistuba II: A prospective, multiinstitutional, pathologist-based assessment of 4 immunohistochemistry assays for PD-L1 expression in non-small cell lung cancer. JAMA Oncol 3(8): 1051-1058, 2017. PMID: 28278348. DOI: $10.1001 /$ jamaoncol.2017.0013

16 Heineman TE, Widman A, Kuan EC, and St John M: The genetic landscape of programmed death ligand-1 (PD-L1) alterations in head and neck cancer. Laryngoscope Investig Otolaryngol 2(3): 99-103, 2017. PMID: 28894827. DOI: 10.1002/lio2.79

17 Maruse Y, Kawano S, Jinno T, Matsubara R, Goto Y, Kaneko N, Sakamoto T, Hashiguchi Y, Moriyama M, Toyoshima T, Kitamura R, Tanaka H, Oobu K, Kiyoshima T and Nakamura S: Significant association of increased PD-L1 and PD-1 expression with nodal metastasis and a poor prognosis in oral squamous cell carcinoma. Int J Oral Maxillofac Surg 47(7): 836-845, 2018. PMID: 29395669. DOI: 10.1016/j.ijom.2018.01.004 
18 Meng Y, Liang H, Hu J, Liu S, Hao X, Wong MSK, Li X and $\mathrm{Hu}$ L: PD-L1 expression correlates with tumor infiltrating lymphocytes and response to neoadjuvant chemotherapy in cervical cancer. J Cancer 9(16): 2938-2945, 2018. PMID: 30123362. DOI: $10.7150 /$ jca.22532

19 Xue S, Hu M, Li P, Ma J, Xie L, Teng F, Zhu Y, Fan B, Mu D and $\mathrm{Yu}$ J: Relationship between expression of PD-L1 and tumor angiogenesis, proliferation, and invasion in glioma. Oncotarget 8(30): 49702-49712, 2017. PMID: 28591697. DOI: 10.18632/ oncotarget.17922

20 Koh YW, Han JH, Yoon DH, Suh C and Huh J: PD-L1 expression correlates with VEGF and microvessel density in patients with uniformly treated classical Hodgkin lymphoma. Ann Hematol 96(11): 1883-1890, 2017. PMID: 28842748. DOI: 10.1007/s00277-017-3115-6

21 Chang CH, Qiu J, O’Sullivan D, Buck MD, Noguchi T, Curtis JD, Chen Q, Gindin M, Gubin MM, van der Windt GJ, Tonc E, Schreiber RD, Pearce EJ and Pearce EL: Metabolic competition in the tumor microenvironment is a driver of cancer progression. Cell 162(6): 1229-1241, 2015. PMID: 26321679. DOI: 10.1016/j.cell.2015.08.016

22 Noman MZ, Desantis G, Janji B, Hasmim M, Karray S, Dessen P, Bronte V and Chouaib S: PD-L1 is a novel direct target of HIF- $1 \alpha$, and its blockade under hypoxia enhanced MDSCmediated T cell activation. J Exp Med 211(5): 781-790, 2014. PMID: 24778419. DOI: 10.1084/jem.20131916

23 Rademakers SE, Span PN, Kaanders JH, Sweep FC, van der Kogel AJ and Bussink J: Molecular aspects of tumour hypoxia. Mol Oncol 2(1): 41-53, 2008. PMID: 19383328. DOI: 10.1016/j.molonc.2008.03.006

24 Kasahara N, Kaira K, Bao P, Higuchi T, Arisaka Y, ErkhemOchir B, Sunaga N, Ohtaki Y, Yajima T, Kosaka T, Oyama T, Yokobori T, Asao T, Nishiyama M, Tsushima Y, Kuwano H, Shimizu K and Mogi A: Correlation of tumor-related immunity with ${ }^{18} \mathrm{~F}-\mathrm{FDG}-\mathrm{PET}$ in pulmonary squamous-cell carcinoma. Lung Cancer 119: 71-77, 2018. PMID: 29656756. DOI: 10.1016/ j.lungcan.2018.03.001

25 Takada K, Toyokawa G, Okamoto T, Baba S, Kozuma Y, Matsubara T, Haratake N, Akamine T, Takamori S, Katsura M, Shoji F, Honda H, Oda Y and Maehara Y: Metabolic characteristics of programmed cell death-ligand 1-expressing lung cancer on ${ }^{18} \mathrm{~F}$-fluorodeoxyglucose positron emission tomography/computed tomography. Cancer Med 6(11): 25522561, 2017. PMID: 28980429. DOI: 10.1002/cam4.1215

26 de Vicente JC, Rodríguez-Santamarta T, Rodrigo JP, BlancoLorenzo V, Allonca E and García-Pedrero JM: PD-L1 expression in tumor cells is an independent unfavorable prognostic factor in oral squamous cell carcinoma. Cancer Epidemiol Biomarkers Prev 28(3): 546-554, 2019. PMID: 30487133. DOI: 10.1158/ 1055-9965.EPI-18-0779
27 Kogashiwa Y, Yasuda M, Sakurai H, Nakahira M, Sano Y, Gonda K, Ikeda T, Inoue H, Kuba K, Oba S, Ishikawa J, Enoki Y, Matsumura S, Minami K, Ebihara Y and Sugasawa M: PDL1 Expression confers better prognosis in locally advanced oral squamous cell carcinoma. Anticancer Res 37(3): 1417-1424, 2017. PMID: 28314313. DOI: 10.21873/anticanres.11465

28 Ahn H, Yang JM, Kim H, Chung JH, Ahn SH, Jeong WJ and Paik JH: Clinicopathologic implications of the miR-197/PD-L1 axis in oral squamous cell carcinoma. Oncotarget 8(39): 6617866194, 2017. PMID: 29029502. DOI: 10.18632/oncotarget. 19842

29 Troiano G, Caponio VCA, Zhurakivska K, Arena C, Pannone G, Mascitti M, Santarelli A and Lo Muzio L: High PD-L1 expression in the tumour cells did not correlate with poor prognosis of patients suffering for oral squamous cells carcinoma: A meta-analysis of the literature. Cell Prolif 52(2): e12537, 2019. PMID: 30443950. DOI: 10.1111/cpr.12537

30 Yang WF, Wong MCM, Thomson PJ, Li KY and Su YX: The prognostic role of PD-L1 expression for survival in head and neck squamous cell carcinoma: A systematic review and metaanalysis. Oral Oncol 86: 81-90, 2018. PMID: 30409325. DOI: 10.1016/j.oraloncology.2018.09.016

31 Shi Y: Regulatory mechanisms of PD-L1 expression in cancer cells. Cancer Immunol Immunother 67(10): 1481-1489, 2018. PMID: 30120503. DOI: 10.1007/s00262-018-2226-9

32 Mandai M, Hamanishi J, Abiko K, Matsumura N, Baba T and Konishi I: Dual faces of IFN $\gamma$ in cancer progression: A role of PD-L1 induction in the determination of pro- and antitumor immunity. Clin Cancer Res 22(10): 2329-2334, 2016. PMID: 27016309. DOI: 10.1158/1078-0432.CCR-16-0224

33 Mandal R, Şenbabaoğlu Y, Desrichard A, Havel JJ, Dalin MG, Riaz N, Lee KW, Ganly I, Hakimi AA, Chan TA and Morris LG: The head and neck cancer immune landscape and its immunotherapeutic implications. JCI Insight 1(17): e89829, 2016. PMID: 27777979. DOI: $10.1172 /$ jci.insight. 89829 